\title{
Outcomes of renal function in elderly patients with acute kidney injury
}

\author{
This article was published in the following Dove Press journal: \\ Clinical Interventions in Aging \\ 18 January 2017 \\ Number of times this article has been viewed
}

\author{
Qinglin $\mathrm{Li}^{\mathrm{l}}$ \\ Meng Zhao ${ }^{2}$ \\ Jing $D u^{\prime}$ \\ Xiaodan Wang ${ }^{1,3}$ \\ 'Department of Geriatric Nephrology, \\ ${ }^{2}$ Department of Clinical Data \\ Repository, ${ }^{3}$ Department of Health \\ Care, Chinese PLA General Hospital, \\ Beijing, People's Republic of China
}

Objectives: The aim of this study was to explore the prognostic impact of clinical factors on the short-term outcomes of renal function (RF) in very elderly patients with acute kidney injury (AKI).

Patients and methods: We carried out a retrospective cohort study of only very elderly patients who developed AKI at the geriatric department of a tertiary medical center during the period 2007-2015. All patients with AKI were followed up for 90 days after AKI diagnosis or until death. Survivors were divided into recovery and nonrecovery groups according to their RF 90 days post-AKI. RF recovery was defined as an estimated glomerular filtration rate (eGFR) of $\geq 60 \mathrm{~mL} / \mathrm{min} / 1.73 \mathrm{~m}^{2}$.

Results: In total, 668 patients $(39.0 \%)$ developed AKI, and 652 patients were included in the final analysis. The median age of this population was 87 years, with $95.6 \%$ being male. The 90-day mortality rate was $33.6 \%$. Of the 433 survivors, $316(73.0 \%)$ recovered to their baseline eGFR. Body mass index (BMI), baseline eGFR, low mean aortic pressure (MAP), low prealbumin level, hypoalbuminemia, oliguria, blood urea nitrogen (BUN) level, and more severe AKI stage were independent risk factors associated with nonrenal recovery or death. AKI etiology, evaluated by peak serum creatinine ( $\mathrm{SCr}$ ) level and the requirement for dialysis, was not associated with nonrenal recovery.

Conclusion: Risk factors for the poor outcomes of RF in very elderly patients with AKI were BMI, baseline eGFR, low MAP, low prealbumin level, hypoalbuminemia, oliguria, BUN level, and more severe AKI stage. Identifying risk factors may help to improve patient outcomes.

Keywords: acute kidney injury, elderly, prognosis, renal function, risk factors

\section{Introduction}

Acute kidney injury (AKI), previously termed as acute renal failure (ARF), is a common acute syndrome characterized by sudden impairment in renal function (RF) caused by a decrease in the glomerular filtration rate (GFR). ${ }^{1}$ Although studies have suggested that the elderly population, particularly among males, is more prone to AKI than younger patients, ${ }^{2}$ few studies have specifically focused on elderly population with AKI.

Patients with AKI are at increased risk for death and chronic kidney disease (CKD). ${ }^{3-6}$ Thus, when evaluating the short- and long-term outcomes of AKI, not only the survival but also the recovery of RF is an important clinical issue. However, focusing on the long-term RF outcomes of geriatric AKI individuals may often be difficult because the prognosis is significantly poor following hospital discharge, and survivors are often left with multiple chronic conditions. ${ }^{3,7}$ Since long-term survival rates may be reduced significantly, short-term consequences, such as mortality and RF outcome, may be more important and practical. 
The rate of RF recovery post-AKI varies in the literature, possibly due to the lack of a consistent definition of what constitutes renal recovery. ${ }^{8,9}$ Previous studies on recovery from AKI-induced RF have focused on clinical outcomes often assessed at the time of hospital discharge,,$^{3,10-13}$ and they defined RF recovery as the weaning of the patient from dialysis or a decrease in serum creatinine ( $\mathrm{SCr}$ ) levels to below a defined threshold. ${ }^{3,10,12-15}$ The prevalence of post-AKI renal recovery in these available studies has varied widely between $33 \%$ and $86 \%{ }^{3,11,12,14,15}$ However, various chronic conditions, refractory pulmonary infection, and the necessity of prolonged mechanical ventilation (MV) can often extend the hospital stays of the elderly. Thus, evaluation of RF recovery and mortality only from the time of hospital discharge is inappropriate, particularly for patients older than 75 years. There are still only a few studies that have reported RF outcome according to AKI severity, ${ }^{12,15}$ and none of these studies used the 2012 Kidney Disease Improving Global Outcomes (KDIGO) criteria to both diagnose AKI and assess recovery. ${ }^{1}$

The objectives of this study were to, 1) compare the rates of complete recovery or nonrecovery from different stages of AKI, as defined by the KDIGO criteria; 2) examine the effect of AKI on short-term RF outcomes and mortality; and 3) identify the rate of recovery from RF at 90 days post-AKI and its risk factors.

\section{Patients and methods}

This was a retrospective cohort study performed in the Geriatric Department of the Chinese PLA General Hospital. We collected data of very elderly patients ( $\geq 75$ years of age) who were treated from January 1, 2007, to December 31, 2015. All patients who developed AKI were enrolled. The study design was approved by the Clinical Ethics Committee of the Chinese PLA General Hospital, and each patient provided written informed consent. Patients were divided into groups of survivors or nonsurvivors based on their survival status at 90 days. Survivors were further divided into recovery and nonrecovery groups based on their RF at 90 days postAKI. To assess the risk factors of prognosis, we separated the patients into 2 groups based on whether they progressed to nonrecovery or died.

AKI was diagnosed with reference (exclusively) to the patient's SCr level, specifically, by an $\mathrm{SCr}$ increase of $\geq 0.3 \mathrm{mg} / \mathrm{dL}$ ( $\geq 26.5 \mu \mathrm{mol} / \mathrm{L}$ ) within $48 \mathrm{~h}$, or a $\geq 1.5$-fold increase relative to the baseline value, known or presumed to have developed within the prior 7 days. ${ }^{1}$ The severity of AKI was defined by the KDIGO staging criteria. Estimated GFRs
(eGFRs) were calculated by the Chronic Kidney Disease Epidemiology Collaboration (CKD-EPI). ${ }^{16}$

We noted the age and gender of patients, body mass index (BMI), comorbidities (history of hypertension, coronary disease, COPD, and diabetes mellitus), time from AKI to diagnosis, etiology of AKI (infection, hypovolemia, cardiovascular events, nephrotoxic drugs, surgery, or uncertain), need for dialysis, need for MV, urine output, and mean aortic pressure (MAP). Other laboratory data of interest included baseline $\mathrm{SCr}, \mathrm{SCr}$ at diagnosis of AKI, peak $\mathrm{SCr}$, blood urea nitrogen (BUN), uric acid, serum prealbumin, albumin, kalemia, serum calcium, serum magnesium, serum phosphate, and hemoglobin.

The baseline SCr level was the most recent stable measure obtained 1-3 months prior to admission with AKI. ${ }^{17,18}$ Peak $\mathrm{SCr}$ was the highest $\mathrm{SCr}$ reached during the episode. The outcome of RF at 90 days post-AKI as indicated by the eGFR was characterized as recovered (eGFR $\geq 60 \mathrm{~mL} / \mathrm{min} / 1.73 \mathrm{~m}^{2}$ ) or nonrecovered $\left(\mathrm{eGFR}<60 \mathrm{~mL} / \mathrm{min} / 1.73 \mathrm{~m}^{2}\right) .{ }^{19,20}$ Oliguria was defined as urinary output $<400 \mathrm{~mL} / 24 \mathrm{~h}$.

We excluded patients younger than 75 years, previously diagnosed with $\mathrm{CKD},{ }^{19}$ stayed in the hospital for $<48 \mathrm{~h}$, had only $1 \mathrm{SCr}$ or no SCr examination, had a missing or incomplete medical history, and who died within $48 \mathrm{~h}$ of hospital admission.

\section{Statistical analysis}

Continuous variables are presented as mean \pm SD values or median ( $25 \%-75 \%$ interquartile range), depending on the variable distribution. Discrete variables are presented as counts or percentages. Statistical analyses were performed using SPSS version 17.0 for Windows (SPSS Inc., Chicago, IL, USA). Between-group comparisons were made using Student's $t$-test or Mann-Whitney $U$ test. Correlations between potential risk factors and renal outcome were assessed using Pearson's chi-squared or Fisher's exact tests. Multivariable logistic regression analyses were performed to identify covariates associated with nonrecovery from AKI. A $P$-value $<0.05$ indicated statistical significance.

\section{Results \\ Baseline characteristics of the enrolled patients}

A total of 3,464 patients were admitted to the Geriatric Department during the study period, and 668 were identified as having AKI. Of these, 16 were excluded for the reasons shown in Figure 1, resulting in 652 patients with AKI suitable for analysis. On day 28 after AKI, 481 patients 


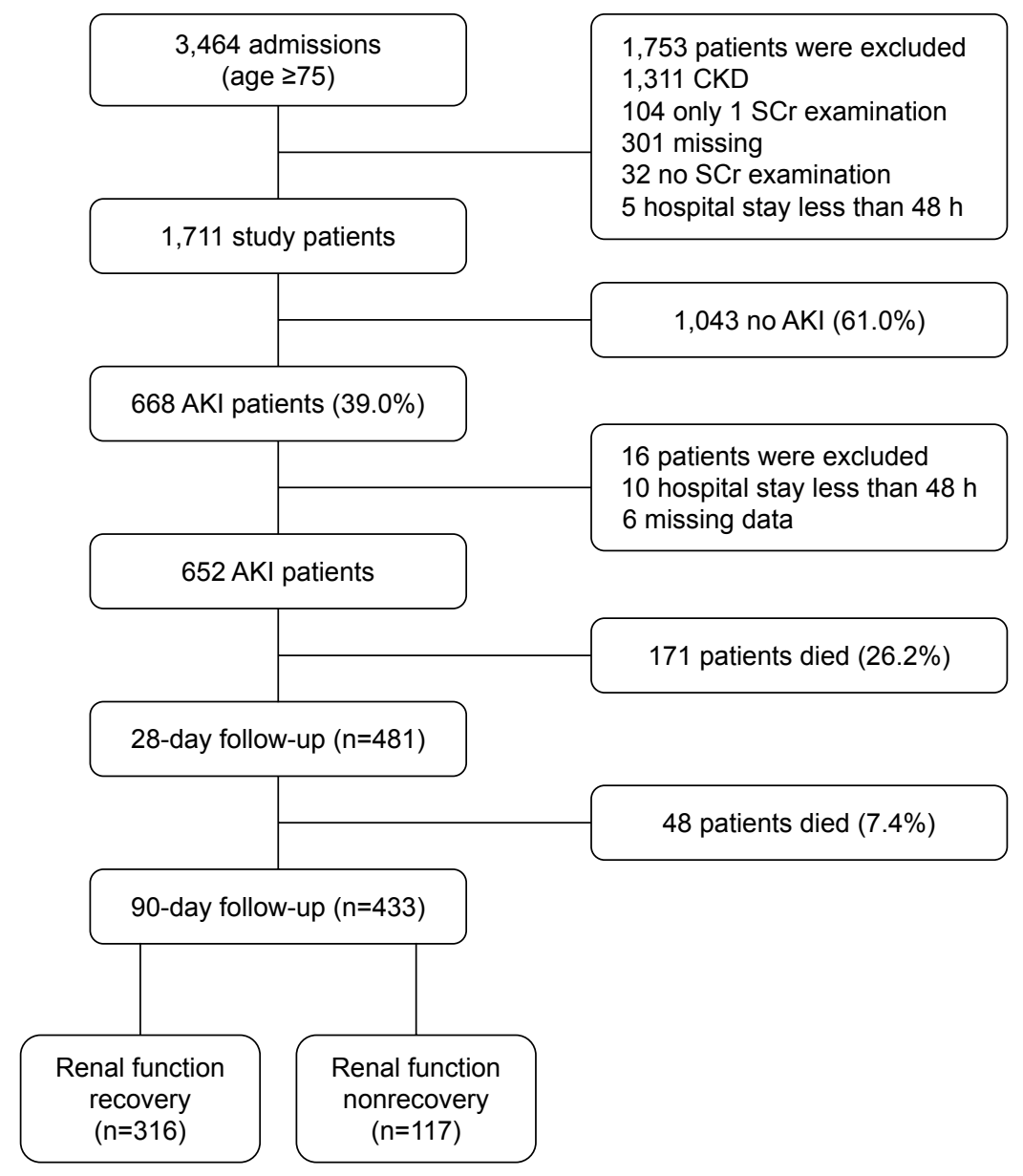

Figure I Flow chart of patient inclusion and exclusion.

Abbreviations: AKI, acute kidney injury; CKD, chronic kidney disease; $\mathrm{SCr}$, serum creatinine.

(73.8\%) were alive, and 171 patients $(26.2 \%)$ were deceased. In all, 219 patients $(33.6 \%)$ died within 90 days. Of the 433 survivors with AKI in whom recovery could be assessed, 316 patients $(73.0 \%)$ recovered to their baseline eGFR, and 117 patients $(27.0 \%)$ developed CKD. Death or no recovery occurred in $336(51.5 \%)$ patients.

\section{Demographic characteristics of elderly patients with AKI}

Baseline characteristics of 652 elderly patients with AKI are shown in Table 1. The median age of the cohort was 87 years, with $95.6 \%$ being male. The median baseline eGFR was $78.4 \mathrm{~mL} / \mathrm{min} / 1.73 \mathrm{~m}^{2}$. Using the KDIGO criteria, 308 patients (47.2\%) were classified as stage 1 AKI, 164 (25.2\%) as stage 2, and $180(27.6 \%)$ as stage 3 . The most common comorbid conditions were coronary disease $(505,77.5 \%)$, hypertension $(485,74.4 \%)$, COPD $(454,69.6 \%)$, and diabetes mellitus $(234,35.8 \%)$. Overall, 240 patients $(36.8 \%)$ required MV, 35 (5.4\%) had oliguria, and 9 (1.4\%) of stage 3 patients required acute dialysis.

\section{The relationship of $\mathrm{AKI}$ etiology with 90-day mortality and RF outcomes}

The most frequent causes of AKI in geriatric patients were infection $(259,39.7 \%)$, hypovolemia $(155,23.8 \%$; volume depletion or hypotension), cardiovascular events $(103,15.8 \%$; acute coronary syndrome or acute heart failure), nephrotoxicity $(78,12.0 \%)$, surgery $(45,6.9 \%)$, and others $(12,1.8 \%)$.

Examination of the difference in prevalence of the most common AKI relative to mortality and RF outcome is shown in Table 2. There was no significant association between the recovery group and the nonrecovery group regarding AKI etiology (all $P>0.05$ ). Nonsurvivors were more likely to have had infections and less nephrotoxic drugs upon AKI diagnosis than were survivors ( $53.0 \%$ vs $33.0 \%, P<0.001$; $5.5 \%$ vs $15.2 \%, P=0.001)$.

\section{Clinical characteristics and 90-day mortality and RF outcomes}

At 90 days, survivors had $73.0 \%$ complete recovery and $27.0 \%$ did not recover. The prevalence rates of eGFR 
Table I Summary of participant characteristics

\begin{tabular}{|c|c|}
\hline Characteristics & Values \\
\hline Age (years) & 87 (84-9I) \\
\hline BMI $\left(\mathrm{kg} / \mathrm{m}^{2}\right)$ & $23.1 \pm 3.2$ \\
\hline \multicolumn{2}{|l|}{ Comorbidity } \\
\hline Coronary disease & $505(77.5)$ \\
\hline Hypertension & $485(74.4)$ \\
\hline COPD & $454(69.6)$ \\
\hline Diabetes & $234(35.8)$ \\
\hline Baseline eGFR $\left(\mathrm{mL} / \mathrm{min} / 1.73 \mathrm{~m}^{2}\right)$ & $78.4(71.2-85.0)$ \\
\hline \multicolumn{2}{|l|}{ Etiology of AKI } \\
\hline Infections & $259(39.7)$ \\
\hline Hypovolemia & $155(23.8)$ \\
\hline Cardiovascular events & $103(15.8)$ \\
\hline Nephrotoxicity & $78(12.0)$ \\
\hline Surgery & $45(6.9)$ \\
\hline Others & $12(1.8)$ \\
\hline \multicolumn{2}{|l|}{ Parameter at the time of $\mathrm{AKI}$ diagnosis } \\
\hline Oliguria & $35(5.4)$ \\
\hline Dialysis & $9(1.4)$ \\
\hline MV & $240(36.8)$ \\
\hline \multicolumn{2}{|l|}{ AKI stage } \\
\hline 1 & $308(47.2)$ \\
\hline 2 & $164(25.2)$ \\
\hline 3 & $180(27.6)$ \\
\hline eGFR 90 days after AKI $\left(\mathrm{mL} / \mathrm{min} / 1.73 \mathrm{~m}^{2}\right)$ & $72.3(56.9-83.0)$ \\
\hline Renal function recovery at 90 days & $316 / 433(73.0)$ \\
\hline 90-day mortality & $219 / 652(33.6)$ \\
\hline
\end{tabular}

levels of $\geq 90 \mathrm{~mL} / \mathrm{min} / 1.73 \mathrm{~m}^{2}, 60-89 \mathrm{~mL} / \mathrm{min} / 1.73 \mathrm{~m}^{2}$, $45-59 \mathrm{~mL} / \mathrm{min} / 1.73 \mathrm{~m}^{2}, 30-44 \mathrm{~mL} / \mathrm{min} / 1.73 \mathrm{~m}^{2}, 15-29 \mathrm{~mL} /$ $\min / 1.73 \mathrm{~m}^{2}$, and $<15 \mathrm{~mL} / \mathrm{min} / 1.73 \mathrm{~m}^{2}$ were $8.3 \%, 64.7 \%$, $18.2 \%, 6.2 \%, 2.1 \%$, and $0.5 \%$, respectively (Figure 2).

As shown in Table 3, no significant difference was evident between the 2 cohorts in terms of comorbidities (coronary disease $P=0.613$, hypertension $P=0.212$, COPD $P=0.397$ and diabetes mellitus $P=0.711)$. Likewise, no differences were found in age $(P=0.878)$ and gender $(P=0.636)$. BMI (22.7 \pm 3.0 vs $23.4 \pm 3.3, P=0.002)$ and baseline eGFR $\left(79.2 \mathrm{~mL} / \mathrm{min} / 1.73 \mathrm{~m}^{2}\right.$ vs $\left.78.0 \mathrm{~mL} / \mathrm{min} / 1.73 \mathrm{~m}^{2}, P<0.001\right)$ differed significantly between the 2 groups.
Upon comparing the 2 groups shown in Table 3, we found that patients with nonrecovery and death had higher $\mathrm{SCr}$ $(137.6 \mu \mathrm{mol} / \mathrm{L}$ vs $125.0 \mu \mathrm{mol} / \mathrm{L}, P<0.001)$ and peak $\mathrm{SCr}$ $(173.3 \mu \mathrm{mol} / \mathrm{L}$ vs $129.8 \mu \mathrm{mol} / \mathrm{L}, P<0.001)$ levels, as well as a higher BUN $(17.0 \mathrm{mmol} / \mathrm{L}$ vs $11.0 \mathrm{mmol} / \mathrm{L}, P<0.001)$ level compared with patients with renal recovery at the time of AKI diagnosis. Of the 336 patients who did not recover, AKI diagnosis occurred 2.0 days (2.0-6.0 days) compared to 3.0 days (2.0-7.0 days) with patients with renal recovery $(P=0.001)$. Low MAP $(75 \pm 13 \mathrm{mmHg}$ vs $82 \pm 14 \mathrm{mmHg}$, $P<0.001$ ), oliguria $(7.7 \%$ vs $2.8 \%, P<0.001$ ), anemia $(107 \pm 23 \mathrm{~g} / \mathrm{L}$ vs $118 \pm 21 \mathrm{~g} / \mathrm{L}, P<0.001)$, a lower prealbumin level (164 g/L vs $198 \mathrm{~g} / \mathrm{L}, P<0.001)$, hypoalbuminemia $(32.9 \pm 5.5 \mathrm{~g} / \mathrm{L}$ vs $35.9 \pm 5.0 \mathrm{~g} / \mathrm{L}, P<0.001)$, higher uric acid $(393 \mu \mathrm{mol} / \mathrm{L}$ vs $348.0 \mu \mathrm{mol} / \mathrm{L}, P<0.001)$ level, magnesium $(0.9 \mathrm{mmol} / \mathrm{L}$ vs $0.9 \mathrm{mmol} / \mathrm{L}, P=0.028)$ level, and phosphate $(1.2 \mathrm{mmol} / \mathrm{L}$ vs $1.2 \mathrm{mmol} / \mathrm{L}, P=0.001)$ level were more frequent among patients who did not recover from RF.

\section{RF outcomes and mortality according to AKI severity}

As expected, full recovery among survivors decreased substantially with increasing AKI severity (from $67.1 \%$ in stage 1 to $10.4 \%$ in stage 3; $P<0.001$; Figure 3).

\section{Risk factors for 90-day outcomes in geriatric patients with AKI}

In the multivariate Cox regression analysis, BMI (hazard ratio $[\mathrm{HR}]=0.956,95 \% \mathrm{CI}$ : $0.923-0.990, P=0.011)$, baseline eGFR (HR $=0.981,95 \%$ CI: 0.968-0.993, $P=0.002$ ), low MAP (HR $=0.980,95 \%$ CI: 0.972-0.988, $P<0.001)$, low prealbumin level $(\mathrm{HR}=0.975,95 \% \mathrm{CI}$ : $0.955-0.995, P=0.015)$, hypoalbuminemia (HR $=0.975,95 \%$ CI: $0.952-0.999, P=0.042$ ), oliguria (HR $=2.007,95 \%$ CI: $1.332-3.025, P=0.001$ ), BUN level (HR $=1.028,95 \%$ CI: $1.018-1.038, P<0.001)$, and more severe AKI stage (stage 2: HR $=1.932,95 \%$ CI: $1.424-2.621$, $P<0.001$; stage 3 : HR $=3.831,95 \%$ CI: 2.786-5.270,

Table 2 Prevalence of the most common AKI causes relative to mortality and renal function outcomes

\begin{tabular}{|c|c|c|c|c|c|c|}
\hline Characteristics & $\begin{array}{l}\text { Nonsurvival group, } \\
\mathrm{n}=219 \text { (33.6) }\end{array}$ & $\begin{array}{l}\text { Survival group, } \\
n=433(66.4)\end{array}$ & $P$-value & $\begin{array}{l}\text { Nonrecovery group, } \\
n=I I 7(27.0)\end{array}$ & $\begin{array}{l}\text { Recovery group, } \\
n=316(73.0)\end{array}$ & $P$-value \\
\hline \multicolumn{7}{|l|}{ Etiology of AKI } \\
\hline Infection & $116(53.0)$ & $143(33.0)$ & $<0.001$ & $34(29.1)$ & $109(34.5)$ & 0.286 \\
\hline Hypovolemia & $53(24.2)$ & $102(23.6)$ & 0.621 & $29(24.8)$ & $73(23.1)$ & 0.714 \\
\hline Cardiovascular events & $27(12.3)$ & $76(17.6)$ & 0.088 & $20(17.1)$ & $56(17.7)$ & 0.879 \\
\hline Nephrotoxicity & $12(5.5)$ & $66(15.2)$ & 0.001 & $20(17.1)$ & $46(14.6)$ & 0.514 \\
\hline Surgery & $9(4.1)$ & $36(8.3)$ & 0.058 & II (9.4) & $25(7.9)$ & 0.618 \\
\hline Others & $2(0.9)$ & $10(2.3)$ & 0.251 & $3(2.6)$ & $7(2.2)$ & 1.000 \\
\hline
\end{tabular}

Note: Values are $\mathrm{n}(\%)$.

Abbreviation: AKI, acute kidney injury. 


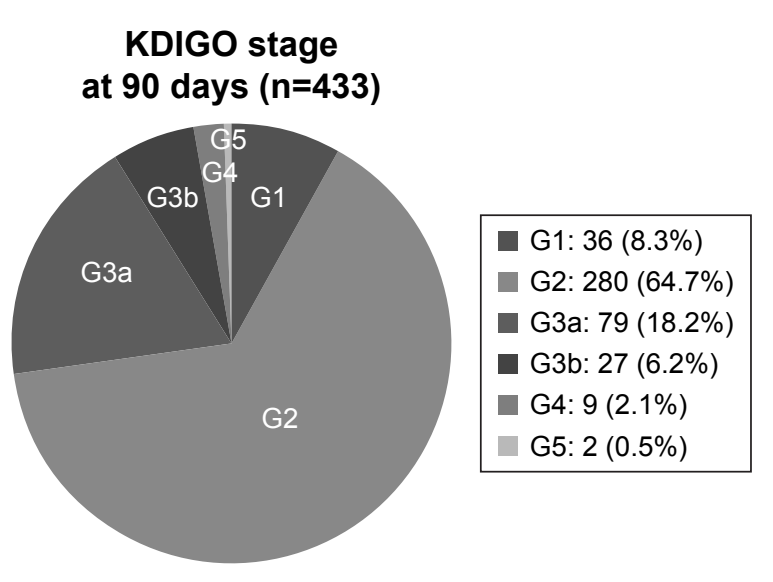

Figure 2 Evolution of renal function according to KDIGO staging.

Notes: GI: $\geq 90 \mathrm{~mL} / \mathrm{min} / \mathrm{l} .73 \mathrm{~m}^{2} ; \mathrm{G} 2: 60-89 \mathrm{~mL} / \mathrm{min} / \mathrm{l} .73 \mathrm{~m}^{2}$; G3a: $45-59 \mathrm{~mL} / \mathrm{min} /$ I.73 $\mathrm{m}^{2}$; G3b: 30-44 mL/min/I.73 m²; G4: 15-29 mL/min/I.73 $\mathrm{m}^{2}$; and G5: <I5 $\mathrm{mL} / \mathrm{min} / \mathrm{l} .73 \mathrm{~m}^{2}$.

Abbreviations: KDIGO, Kidney Disease Improving Global Outcomes; G, glomerular filtration rate category.

$P<0.001)$ were independent risk factors for 90-day poor outcomes after AKI development (Table 4).

\section{Discussion}

As results of the present study indicate, in a very elderly population, aged 75 years and older, up to $27 \%$ of AKI survivors developed CKD stage 3-5, during a 90-day follow-up period. To the best of our knowledge, no previous research has evaluated short-term mortality and RF outcome after AKI in very elderly patients, particularly using the complete standardized KDIGO criteria.

In the very elderly, the development of clinically relevant AKI is associated with age-dependent changes, which are independent risk factors for AKI. Such changes render older patients more prone to medication-associated toxicities and ischemic injury. Furthermore, elderly individuals are very vulnerable to coexisting illness and are more likely to require surgery. Often, multidrug combination therapy is required; this is a prime trigger of AKI. In the present study, multivariable Cox regression analysis showed that the etiology of AKI was not a risk factor for 90-day RF nonrecovery.

Most clinical studies of RF recovery from AKI usually evaluated outcome at hospital discharge, and the most frequent outcome definitions were limited to the necessity of dialysis. Few studies have evaluated the recovery from less severe forms of AKI. They used return-to-baseline $\mathrm{SCr},{ }^{12,21}$ normalization of $\mathrm{SCr},{ }^{3}$ return-to-baseline eGFR, ${ }^{22}$ or absence of AKI criteria at discharge, ${ }^{23}$ all based on comparisons of

Table 3 Comparisons of clinical characteristics of elderly patients with AKI according to mortality and renal function outcomes

\begin{tabular}{|c|c|c|c|c|}
\hline Characteristics & $\begin{array}{l}\text { Patients with } \\
\text { AKI }(n=652)\end{array}$ & $\begin{array}{l}\text { Nonrecovery and death } \\
\text { group, } n=336(51.5)\end{array}$ & $\begin{array}{l}\text { Recovery group, } \\
n=316(48.5)\end{array}$ & $P$-value \\
\hline Age (years) & $87(84-91)$ & $88(84-9 \mid)$ & $87(84-91)$ & 0.878 \\
\hline Male & $623(95.6)$ & $321(95.5)$ & $302(95.6)$ & 0.636 \\
\hline BMI $\left(\mathrm{kg} / \mathrm{m}^{2}\right)$ & $23.1 \pm 3.2$ & $22.7 \pm 3.0$ & $23.4 \pm 3.3$ & 0.002 \\
\hline \multicolumn{5}{|l|}{ Comorbidity } \\
\hline Coronary disease & $505(77.5)$ & $264(78.6)$ & $24 \mid(76.3)$ & 0.613 \\
\hline Hypertension & $485(74.4)$ & $245(72.9)$ & $240(75.9)$ & 0.212 \\
\hline COPD & $454(69.6)$ & $229(68.2)$ & $225(7 I .2)$ & 0.397 \\
\hline Diabetes & $234(35.8)$ & $115(34.2)$ & $119(37.7)$ & 0.711 \\
\hline Baseline eGFR (mL/min/l.73 $\left.\mathrm{m}^{2}\right)$ & $78.4(71.2-85.0)$ & $79.2(69.8-86.0)$ & $78.0(71.7-83.6)$ & $<0.001$ \\
\hline Time for AKI to develop (days) & $2.0(2.0-7.0)$ & $2.0(2.0-6.0)$ & $3.0(2.0-7.0)$ & 0.001 \\
\hline \multicolumn{5}{|c|}{ Parameter at the time of AKI diagnosis } \\
\hline $\mathrm{MAP}(\mathrm{mmHg})$ & $78 \pm 14$ & $75 \pm 13$ & $82 \pm 14$ & $<0.001$ \\
\hline Oliguria & $35(5.4)$ & $26(7.7)$ & $9(2.8)$ & $<0.001$ \\
\hline Dialysis & $9(1.4)$ & $9(2.7)$ & 0 & 0.014 \\
\hline $\mathrm{MV}$ & $240(36.8)$ & $162(48.2)$ & $78(24.7)$ & $<0.001$ \\
\hline \multicolumn{5}{|c|}{ Laboratory results at the time of $A K I$ diagnosis } \\
\hline $\mathrm{SCr}(\mu \mathrm{mol} / \mathrm{L})$ & | $31.4(|17.5-| 47.0)$ & $137.6(\mid 23.0-156.0)$ & $125.0(|| 3.7-138.3)$ & $<0.001$ \\
\hline Peak SCr $(\mu \mathrm{mol} / \mathrm{L})$ & | 43.7 (| 24.0-200.0) & $173.3(138.6-269.4)$ & $129.8(\mid 16.0-147.9)$ & $<0.001$ \\
\hline $\mathrm{BUN}(\mathrm{mmol} / \mathrm{L})$ & $12.6(8.8-20.9)$ & $17.0(9.8-26.6)$ & $11.0(8.0-15.6)$ & $<0.001$ \\
\hline Uric acid (mmol/L) & $364.9(290.0-467.0)$ & $393.0(300.2-497.8)$ & $348.0(281.3-430.4)$ & $<0.001$ \\
\hline Prealbumin $(g / L)$ & $181.0(\mid 40.0-231.0)$ & $164(126-216)$ & $198(156-247)$ & $<0.001$ \\
\hline Albumin $(g / L)$ & $34.3 \pm 5.5$ & $32.9 \pm 5.5$ & $35.9 \pm 5.0$ & $<0.001$ \\
\hline Magnesium (mmol/L) & $0.9(0.8-1.0)$ & $0.9(0.8-1.0)$ & $0.9(0.8-1.0)$ & 0.028 \\
\hline Calcium (mmol/L) & $2.2(2.1-2.3)$ & $2.2(2.1-2.3)$ & $2.2(2.1-2.4)$ & 0.431 \\
\hline Phosphate (mmol/L) & $1.2(1.0-1.5)$ & $1.2(1.0-1.5)$ & $1.2(0.9-1.4)$ & 0.001 \\
\hline Hemoglobin $(g / L)$ & $112 \pm 23$ & $107 \pm 23$ & || $8 \pm 2 \mid$ & $<0.001$ \\
\hline
\end{tabular}

Notes: Values are $\mathrm{n}(\%)$, mean $\pm \mathrm{SD}$, or median (interquartile range). $1 \mathrm{mmHg}=0.133 \mathrm{kPa}$.

Abbreviations: AKI, acute kidney injury; BMI, body mass index; BUN, blood urea nitrogen; eGFR, estimated glomerular filtration rate; MAP, mean aortic pressure; $\mathrm{MV}$, mechanical ventilation; SCr, serum creatinine. 


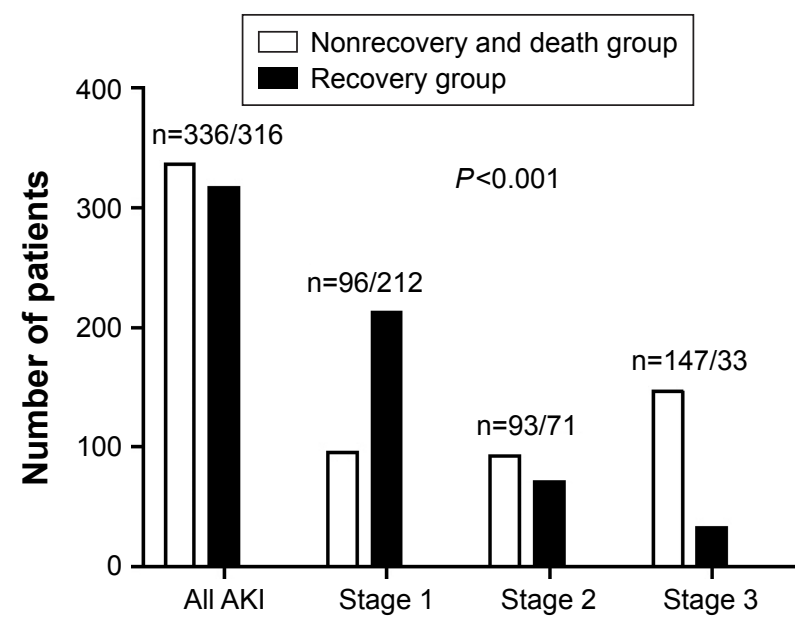

Figure 3 Renal function outcomes and mortality of different AKI stages in patients with AKI.

Abbreviation: $\mathrm{AKI}$, acute kidney injury.

discharge $\mathrm{SCr}$, or the derived eGFR, with baseline $\mathrm{SCr}$ or eGFR. These criteria are associated with different rates of renal recovery depending on the study being evaluated. Ali et al published a study with 474 patients with AKI using Risk, Injury, Failure, Loss and End-stage Kidney Disease (RIFLE) definition. ${ }^{21}$ They reported that among those patients with normal RF before AKI, 92\% had a complete RF recovery (SCr returned to baseline value), 7\% had partial recovery (normalization of $\mathrm{SCr}$ ), and only $0.6 \%$ had no recovery (remained on dialysis for $>3$ months after discharge). Pannu et $\mathrm{al}^{3}{ }^{3}$ in a population-based cohort, found a $70 \%$ recovery rate (defined as SCr within $25 \%$ of their baseline at 90 days after discharge) and 30\% nonrecovery rate. In a retrospective observational study, Thongprayoon et $\mathrm{al}^{24}$ reported a $34 \%$ renal recovery (independence from dialysis by

Table 4 Factors associated with 90 -day outcomes as indicated by Cox regression

\begin{tabular}{llll}
\hline Risk factors & HR & $\mathbf{9 5 \%} \mathbf{~ C l}$ & $\boldsymbol{P}$-value \\
\hline BMI & 0.956 & $0.923-0.990$ & $0.01 \mathrm{I}$ \\
Baseline eGFR & $0.98 \mathrm{I}$ & $0.968-0.993$ & 0.002 \\
Prealbumin level & 0.975 & $0.955-0.995$ & 0.015 \\
Albumin & 0.975 & $0.952-0.999$ & 0.042 \\
MAP & 0.980 & $0.972-0.988$ & $<0.00 \mathrm{I}$ \\
Oliguria & 2.007 & $1.332-3.025$ & $0.00 \mathrm{I}$ \\
BUN level & 1.028 & $1.018-1.038$ & $<0.00 \mathrm{I}$ \\
AKI stage & & & $<0.00 \mathrm{I}$ \\
$\quad$ Stage I & Reference & Reference & \\
Stage 2 & 1.932 & $1.424-2.62 \mathrm{I}$ & $<0.00 \mathrm{I}$ \\
Stage 3 & $3.83 \mathrm{I}$ & $2.786-5.270$ & $<0.00 \mathrm{I}$ \\
\hline
\end{tabular}

Note: I mmHg $=0.133 \mathrm{kPa}$.

Abbreviations: AKI, acute kidney injury; BMI, body mass index; BUN, blood urea nitrogen; eGFR, estimated glomerular filtration rate; HR, hazard ratio; MAP, mean aortic pressure.
90 days) rate in post-cardiac surgery patients who required dialysis. However, studies that consider renal recovery as independence from dialysis can show higher recovery rates than those that evaluate patients with AKI based on baseline SCr. ${ }^{25}$ Additionally, studies using a discharge $\mathrm{SCr}$ to assess renal outcome in elderly patients with AKI can overestimate the incidence of renal recovery. ${ }^{26}$ We used a very restrictive definition of renal recovery (ie, return to eGFR $\geq 60 \mathrm{~mL} / \mathrm{min} / 1.73 \mathrm{~m}^{2}$ rather than to $\mathrm{SCr}$ ), because using eGFR enabled us to classify the patients according to their KDIGO stage of chronic disease. Applying such a definition, we found that $73 \%$ of our AKI survivors had a complete recovery at 90 days.

Another important issue is determining at what point renal recovery must be evaluated, ie, at hospital discharge, after 28 days, after 90 days, etc. In our study, evaluation of RF outcome was performed 90 days after an AKI episode according to the KDIGO AKI guidelines. ${ }^{1}$ We did not use hospital discharge as a time point to assess recovery. Because various chronic conditions in the very elderly often extend the hospital stays, hospital discharge might not be an optimal time point at which to assess AKI recovery. In addition, CKD is defined as eGFR $<60 \mathrm{~mL} / \mathrm{min} / 1.73 \mathrm{~m}^{2}$ for $\geq 3$ months; hence, assessing RF at 90 days can best describe the incidence of CKD.

It is important to identify the predictors associated with death or renal nonrecovery. Our analysis suggests that BMI, baseline eGFR, low MAP, low prealbumin level, hypoalbuminemia, oliguria, BUN level, and more severe AKI stage were independent risk factors associated with death or renal nonrecovery. Other studies have identified advanced age, preexisting diabetes mellitus, decreased baseline eGFR, ${ }^{27}$ higher Charlson comorbidity index score, ${ }^{28}$ or hypomagnesemia ${ }^{23}$ as risk factors for renal nonrecovery in AKI survivors. Following a community-based study of patients older than 65 years, Sesso et al found a relationship between the rate of decline in eGFR with age and baseline eGFR, a result similar to that observed by Collins et al. ${ }^{29,30}$ In contrast, Schiffl did not find any prognostic indicators related to partial recovery (defined as $\mathrm{SCr}>115 \mu \mathrm{mol} / \mathrm{L}$ at hospital discharge) when analyzing 226 critically ill patients with previous normal RF who had AKI requiring dialysis. ${ }^{25}$ James et al, studying older patients following coronary angiography, observed that the patients who developed AKI were more prone to nonrenal recovery beyond 90 days after the angiography and were more likely to progress toward end-stage renal disease (ESRD). ${ }^{31}$ These adverse effects were associated with the severity of AKI. ${ }^{26,31}$ In our cohort, however, the 
peak SCr level and the need for dialysis (both indicative of AKI severity) were not independent factors associated with renal nonrecovery in the multivariate regression.

In the present study, dialysis was performed in only 9 cases (1.4\%) during follow-up; 6 patients died within 90 days, and the other 3 became dependent on dialysis during the analysis period. Thus, the results of this study might be indicating a better-than-usual short-term outcome after AKI: only $0.5 \%$ of patients progressed to ESRD.

Strengths of this study include the elderly age of the sample, the use of a consensus definition for $\mathrm{AKI} / \mathrm{CKD}$ diagnosis and stages, and baseline SCr being available in the entire sample of included patients. On the other hand, limitations of this study should be noted. First, this was a single-center retrospective work, so the results may not be immediately applicable to other hospitalized patients. Second, we analyzed data from a veteran's hospital, and most patients were retired elderly males and fewer females are treated in our hospital. Thus, biased results may be unavoidable. Third, the definition of AKI in our analysis was based on SCr levels. We chose not to use the urine output criteria because these data were incomplete. Fourth, the number of female patients in all AKI groups and the need for dialysis were too small to determine the role in RF outcomes.

\section{Conclusion}

BMI, baseline eGFR, low MAP, low prealbumin level, hypoalbuminemia, oliguria, BUN level, and more severe AKI stage are significant high risk prognostic factors for poor outcome of RF in very elderly patients with AKI. Identification of these factors might lead to more intensive monitoring and early prevention and could improve outcomes for very elderly patients with AKI.

\section{Acknowledgments}

This manuscript was edited for English language by American Journal Experts (AJE). This study was funded by grants from the National Natural Science Foundation of China (No 81370452).

\section{Disclosure}

The authors report no conflicts of interest in this work.

\section{References}

1. Eknoyan G, Lameire N, Eckardt K, Kasiske B. Kidney disease: improving global outcomes (KDIGO) acute kidney injury work group. KDIGO clinical practice guideline for acute kidney injury. Kidney Int Suppl. 2012;2:1-138.

2. Anderson S, Eldadah B, Halter JB, et al. Acute kidney injury in older adults. J Am Soc Nephrol. 2011;22(1):28-38.
3. Pannu N, James M, Hemmelgarn B, Klarenbach S; Alberta Kidney Disease Network. Association between AKI, recovery of renal function, and long-term outcomes after hospital discharge. Clin J Am Soc Nephrol. 2013;8(2):194-202.

4. Chawla LS, Kimmel PL. Acute kidney injury and chronic kidney disease: an integrated clinical syndrome. Kidney Int. 2012;82(5):516-524.

5. Rewa O, Bagshaw SM. Acute kidney injury-epidemiology, outcomes and economics. Nat Rev Nephrol. 2014;10(4):193-207.

6. Nisula S, Kaukonen KM, Vaara ST, et al. Incidence, risk factors and 90-day mortality of patients with acute kidney injury in Finnish intensive care units: the FINNAKI study. Intensive Care Med. 2013;39(3): $420-428$.

7. Coca SG. Acute kidney injury in elderly persons. Am J Kidney Dis. 2010;56(1):122-131.

8. Coca SG, Yusuf B, Shlipak MG, Garg AX, Parikh CR. Long-term risk of mortality and other adverse outcomes after acute kidney injury: a systematic review and meta-analysis. Am J Kidney Dis. 2009;53(6): 961-973.

9. Wald R, Quinn RR, Luo J, et al. Chronic dialysis and death among survivors of acute kidney injury requiring dialysis. JAMA. 2009;302(11): 1179-1185.

10. Lai TS, Wang CY, Pan SC, et al. Risk of developing severe sepsis after acute kidney injury: a population-based cohort study. Crit Care. 2013;17(5):R231.

11. Wu VC, Huang TM, Lai CF, et al. Acute-on-chronic kidney injury at hospital discharge is associated with long-term dialysis and mortality. Kidney Int. 2011;80(11):1222-1230.

12. Wehbe E, Duncan AE, Dar G, Budev M, Stephany B. Recovery from AKI and short- and long-term outcomes after lung transplantation. Clin J Am Soc Nephrol. 2013;8(1):19-25.

13. Gammelager H, Christiansen CF, Johansen MB, Tonnesen E, Jespersen B, Sorensen HT. Three-year risk of cardiovascular disease among intensive care patients with acute kidney injury: a population-based cohort study. Crit Care. 2014;18(5):492.

14. Hobson CE, Yavas S, Segal MS, et al. Acute kidney injury is associated with increased long-term mortality after cardiothoracic surgery. Circulation. 2009;119(18):2444-2453.

15. Bihorac A, Yavas S, Subbiah S, et al. Long-term risk of mortality and acute kidney injury during hospitalization after major surgery. Ann Surg. 2009;249(5):851-858.

16. Levey AS, Stevens LA, Schmid CH, et al. A new equation to estimate glomerular filtration rate. Ann Intern Med. 2009;150(9):604-612.

17. Hsu CY, Chertow GM, McCulloch CE, Fan D, Ordonez JD, Go AS. Nonrecovery of kidney function and death after acute on chronic renal failure. Clin J Am Soc Nephrol. 2009;4(5):891-898.

18. Chao CT, Tsai HB, Wu CY, et al. The severity of initial acute kidney injury at admission of geriatric patients significantly correlates with subsequent in-hospital complications. Sci Rep. 2015;5:13925.

19. Levin A, Stevens PE. Summary of KDIGO 2012 CKD Guideline: behind the scenes, need for guidance, and a framework for moving forward. Kidney Int. 2014;85(1):49-61.

20. Macedo E, Zanetta DM, Abdulkader RC. Long-term follow-up of patients after acute kidney injury: patterns of renal functional recovery. PLoS One. 2012;7(5):e36388.

21. Ali T, Khan I, Simpson W, et al. Incidence and outcomes in acute kidney injury: a comprehensive population-based study. J Am Soc Nephrol. 2007; 18(4):1292-1298.

22. Fortrie G, Stads S, de Geus HR, Groeneveld AB, Zietse R, Betjes MG. Determinants of renal function at hospital discharge of patients treated with renal replacement therapy in the intensive care unit. J Crit Care. 2013;28(2):126-132.

23. Alves SC, Tomasi CD, Constantino L, et al. Hypomagnesemia as a risk factor for the non-recovery of the renal function in critically ill patients with acute kidney injury. Nephrol Dial Transplant. 2013;28(4):910-916.

24. Thongprayoon C, Cheungpasitporn W, Shah IK, et al. Long-term outcomes and prognostic factors for patients requiring renal replacement therapy after cardiac surgery. Mayo Clin Proc. 2015;90(7):857-864. 
25. Schiffl H. Renal recovery from acute tubular necrosis requiring renal replacement therapy: a prospective study in critically ill patients. Nephrol Dial Transplant. 2006;21(5):1248-1252.

26. Schetz M, Gunst J, De Vlieger G, Van den Berghe G. Recovery from AKI in the critically ill: potential confounders in the evaluation. Intensive Care Med. 2015;41(9):1648-1657.

27. Amdur RL, Chawla LS, Amodeo S, Kimmel PL, Palant CE. Outcomes following diagnosis of acute renal failure in U.S. veterans: focus on acute tubular necrosis. Kidney Int. 2009;76(10):1089-1097.

28. Harel Z, Bell CM, Dixon SN, et al. Predictors of progression to chronic dialysis in survivors of severe acute kidney injury: a competing risk study. BMC Nephrol. 2014;15:114.
29. Sesso R, Prado F, Vicioso B, Ramos LR. Prospective study of progression of kidney dysfunction in community-dwelling older adults. Nephrology. 2008;13(2):99-103.

30. Collins AJ, Foley RN, Herzog C, et al. US renal data system 2012 annual data report. Am J Kidney Dis. 2013;61(1 suppl 1):e1-e476.

31. James MT, Ghali WA, Tonelli M, et al. Acute kidney injury following coronary angiography is associated with a long-term decline in kidney function. Kidney Int. 2010;78(8):803-809.
Clinical Interventions in Aging

\section{Publish your work in this journal}

Clinical Interventions in Aging is an international, peer-reviewed journal focusing on evidence-based reports on the value or lack thereof of treatments intended to prevent or delay the onset of maladaptive correlates of aging in human beings. This journal is indexed on PubMed Central, MedLine,

\section{Dovepress}

CAS, Scopus and the Elsevier Bibliographic databases. The manuscript management system is completely online and includes a very quick and fair peer-review system, which is all easy to use. Visit http://www.dovepress. com/testimonials.php to read real quotes from published authors. 